Trinity University

Digital Commons @ Trinity

Psychology Faculty Research

Psychology Department

$10-10-2013$

\title{
Suppression-Induced Reduction in the Specificity of Autobiographical Memories
}

\author{
Elizabeth Stephens \\ Trinity University \\ Amy Braid \\ Trinity University \\ Paula T. Hertel \\ TrinityUniversity, phertel@trinity.edu
}

Follow this and additional works at: https://digitalcommons.trinity.edu/psych_faculty

Part of the Psychology Commons

Publication Details

Clinical Psychological Science

\section{Repository Citation}

Stephens, E., Braid, A., \& Hertel, P.T. (2013). Suppression-induced reduction in the specificity of autobiographical memory. Clinical Psychological Science, 1(2), 163-169. doi: 10.1177/

2167702612467773

This Article is brought to you for free and open access by the Psychology Department at Digital Commons @ Trinity. It has been accepted for inclusion in Psychology Faculty Research by an authorized administrator of Digital Commons@ Trinity. For more information, please contact jcostanz@trinity.edu. 


\title{
Suppression-Induced Reduction in the Specificity of Autobiographical Memories
}

Clinical Psychological Science I (2) $163-169$

(c) The Author(s) 2013

Reprints and permission:

sagepub.com/journalsPermissions.nav DOI: $10.1177 / 2167702612467773$

http://cpx.sagepub.com

@SAGE

\author{
Elizabeth Stephens, Amy Braid, and Paula T. Hertel \\ Trinity University
}

\begin{abstract}
To extend its relevance to everyday forgetting, we applied the think/no-think (TNT) suppression method devised by M. C. Anderson and Green to autobiographical memories. Dysphoric and nondysphoric participants first generated autobiographical memories and corresponding titles to neutral and emotionally positive or negative cues. During the TNT phase, participants repeatedly practiced responding to some cues with their associated titles and avoiding thoughts about titles and memories associated with other cues. Later, they were asked to report memories associated with all cues, including baseline cues not presented during the TNT phase. Results revealed impaired recall, as measured by reductions in specificity, for suppressed memories relative to baseline memories. Also, regardless of TNT instructions, memories of dysphoric students who had received negative cues became less specific and less negative than they were at the outset.
\end{abstract}

\section{Keywords}

suppression, depression, dysphoria, forgetting, overgeneral memory

Received 29/05//2; Revision accepted 09//0/12

Although forgetting the details of events from one's personal past is generally viewed as a negative outcome, it may serve an adaptive function, especially when the environment contains inescapable reminders of negative events. M. C. Anderson and Huddleston (2012) proposed that repeatedly suppressing thoughts of an autobiographical experience eventually leads to its persistent forgetting and that individuals might purposefully suppress thoughts of negative autobiographical experiences to promote emotional stability and resilience in response to frequent reminders. Although their review reveals plentiful evidence for the effectiveness of suppression-induced forgetting (SIF) of laboratory materials, associated effects on autobiographical memory and the concomitant emotional impact seemed to have gone undiscovered. We therefore developed a method to initiate their investigation and applied it to memories generated by dysphoric and nondysphoric students in response to emotional and nonemotional cues.

To vary retrieval suppression, we used the think/no-think (TNT) suppression paradigm developed by M. C. Anderson and Green (2001). In the typical TNT task, participants first study neutral, weakly related cue-target word pairs. In the next phase, some studied cues repeatedly signal the practice of target recall, others signal avoidance of all thoughts of the targets, and the remaining, nonpresented cues are reserved to function as baseline items on the final test, in which recall of all targets is requested. Reduced recall of suppressed targets, compared to baseline targets, constitutes evidence for SIF. Initially, research using the TNT paradigm was designed in ways that were difficult to generalize to everyday experience, but not for long. Variations of the basic paradigm have revealed SIF when verbal cues and targets are related (e.g., Hertel, Large, Stück, \& Levy, 2012; Hertel \& McDaniel, 2010). SIF also occurs with pictorial and emotional stimuli (e.g., Depue, Banich, \& Curran, 2006; Hertel \& McDaniel, 2010; Joormann, Hertel, Brozovich, \& Gotlib, 2005; Joormann, Hertel, LeMoult, \& Gotlib, 2009), when the need to suppress can be anticipated (Hanslmayr, Leipold, \& Bauml, 2010), and when the test itself is an indirect measure of forgetting (Hertel et al., 2012). Yet, until recently, all evidence of SIF had involved experimentally supplied events. ${ }^{1}$ The current study was the first, to our knowledge, to extend the TNT paradigm to autobiographical memories and thus to examine the effects of repeated suppression on memory for multimodal, personally relevant material.

In our adaptation of the TNT procedure, participants first generated autobiographical memories and titles to neutral and emotionally positive or negative cues. During the TNT phase,

Corresponding Author:

Paula T. Hertel, Department of Psychology, Trinity University, I Trinity Place, San Antonio, TX 782I2.

E-mail: phertel@trinity.edu 
they practiced responding to some of the cues with their associated titles and suppressing thoughts about the titles and memories related to other cues. Then, after a brief distracting task, participants attempted to recall titles and memories associated with all cues - cues for response practice, cues for suppression, and baseline cues. We examined SIF in the traditional sense by scoring accuracy of the memory's gist, but because it seemed unlikely that participants would forget the gist of recently recalled, personally meaningful events, we focused instead on a measure of memory impairment that is common in studies of autobiographical memory.

Overgeneral memory is a phenomenon characterized by the restriction of autobiographical recall to a general level, perhaps due to the avoidance of details that might evoke emotion (Williams et al., 2007). It is typically assessed by administering the Autobiographical Memory Test (AMT; Williams \& Broadbent, 1986), a set of one-word cues and the instruction to produce specific memories - events that occurred within a time frame of 1 day. Recalled memories that fail to comply with these instructions are denoted as categorical (events that occurred several times) or extended (events occurring over an extended period of time), although the difference between these failures was not important for our purpose of investigating loss of specificity following suppression practice. Categorical memories are typically schematic in nature (e.g., "my mother used to make my lunch"); extended memories also tend to omit details (e.g., "my father worked while we were in Florida on vacation"). Both types of generality suited our purpose, and therefore, they were not distinguished.

Previous studies have examined overgeneral memory as a consequence of thought suppression, although not in the context of the TNT paradigm, and have shown that suppressing thoughts of a single event leads to subsequent overgeneral recall for other, unrelated memories (Dalgleish \& Yiend, 2006; Schönfeld, Ehlers, Böllinghaus, \& Rief, 2007). To our knowledge, studies of direct suppression and autobiographical memory have not examined the effect of suppressing particular memories on their subsequent recall. Consistent with the typical TNT approach, we predicted reduced specificity of suppressed memories relative to baseline, unpracticed memories.

Two additional features of the experiment are important. First, it remains unclear whether emotionally negative, positive, and neutral materials are equally vulnerable to the effects of suppression practice. Some studies have found greater rates of below-baseline forgetting for emotionally negative material (e.g., Joormann et al., 2005; Lambert, Good, \& Kirk, 2010), whereas others have found no differences (e.g., Hertel \& Gerstle, 2003). Thus, we decided to explore the role of valence by having each participant generate autobiographical memories to both neutral and emotionally positive or negative cues. Second, to examine state-related differences, we recruited both dysphoric and nondysphoric individuals. Dysphoric and depressed individuals more often exhibit reduced memory specificity (Williams et al., 2007), and they may be more motivated to suppress thoughts of their personal pasts - thoughts about emotionally negative events in particular. On the other hand, because of impaired cognitive control in suppressing thoughts during TNT (Hertel \& Gerstle, 2003), dysphoric participants might not show changes in specificity as a function of suppression practice. In summary, we predicted suppressioninduced reductions in the specificity of autobiographical memories - reductions that might be qualified by the emotional characteristics of the cues and the negative affect of the participants. The outcome should inform our inclinations to recommend thought suppression as a method of preventing or interrupting ruminative tendencies and improving resilience when there are no longer benefits to be achieved by remembering memorial details.

\section{Method \\ Participants and design}

Sixty-seven female students were recruited on the basis of their scores on a modified version of the Beck Depression Inventory (BDI-II; Beck, Steer, \& Brown, 1996), completed during screening. Students who scored 13 or higher were recruited to participate as dysphoric (see Dozois, Dobson, \& Ahnberg, 1998) and those who scored 5 or lower were recruited to participate as nondysphoric. A second BDI-II was administered at the end of the experimental session, and data from 7 students were set aside because their final scores were less than 10 in the dysphoric group or greater than 8 in the nondysphoric group. ${ }^{2}$ (Descriptive statistics are listed in Table 1.)

All participants received both neutral and emotional cues. With the constraint of equal $n$, participants were randomly assigned to receive either positive or negative emotional cues and to one of three counterbalancing conditions for rotating materials across the TNT instructional conditions of responding, suppressing, or baseline.

\section{Materials and procedure}

Trait descriptors were chosen as AMT cues (N. Anderson, 1968) on the basis of likeability ratings less than 200 (negative cues; e.g., offensive, jealous), from 250 to 350 (neutral; e.g., innocent, bashful), and greater than 450 (positive; e.g., generous, humorous). Within each valence, cues were distributed into three sets of five, and sets were balanced for likeability, frequency, and word length. One additional cue representing each valence served as practice.

At the start, participants completed a visual analogue scale (VAS) to record the extent to which they felt pessimistic or optimistic, happy or sad, and distressed or calm (each scale ranging from 0 to 100). In the memory-generation phase, participants responded to each computer-displayed cue by retrieving a specific autobiographical memory, defined as an event in their personal past that occurred within 1 day. Cues were ordered in five randomized blocks (three emotional and three neutral cues per block, each representing one of the three instructional conditions during the next phase). Participants 
Table I. Mean Responses (Standard Deviations)

\begin{tabular}{|c|c|c|c|c|}
\hline \multirow[b]{2}{*}{ Measure } & \multicolumn{2}{|c|}{ Nondysphoric } & \multicolumn{2}{|c|}{ Dysphoric } \\
\hline & $\begin{array}{l}\text { Neutral and } \\
\text { positive cues }\end{array}$ & $\begin{array}{l}\text { Neutral and } \\
\text { negative cues }\end{array}$ & $\begin{array}{l}\text { Neutral and } \\
\text { positive cues }\end{array}$ & $\begin{array}{l}\text { Neutral and } \\
\text { negative cues }\end{array}$ \\
\hline BDI-II & $3.5(2.1)$ & $3.6(2.6)$ & I7.3 (6.5) & I7.9 (7.0) \\
\hline \multicolumn{5}{|l|}{ Proportion specific } \\
\hline Generation & $.96(.046)$ & $.94(.078)$ & $.96(.034)$ & $.96(.056)$ \\
\hline Final recall & $.89(.086)$ & $.89(.089)$ & $.90(.059)$ & $.84(.144)$ \\
\hline Reduction & .07 & .06 & .06 & .12 \\
\hline \multicolumn{5}{|l|}{ Valence ratings } \\
\hline Generation & $5.09(.30)$ & $5.95(.29)$ & $5.04(.33)$ & $6.22(.25)$ \\
\hline Final recall & $5.19(.28)$ & $5.87(.16)$ & $5.01(.35)$ & $5.97(.19)$ \\
\hline Average & 5.14 & 5.91 & 5.02 & 6.09 \\
\hline Change & -.10 & .08 & .03 & .25 \\
\hline \multicolumn{5}{|l|}{ VAS for calm } \\
\hline Before generation & $65(20.9)$ & 77 (12.9) & $5 I(20.1)$ & $48(22.4)$ \\
\hline After generation & $74(16.7)$ & $76(15.9)$ & $50(24.7)$ & $61(22.2)$ \\
\hline After TNT & $73(15.8)$ & 78 (16.9) & $5 I(23.1)$ & $65(18.6)$ \\
\hline
\end{tabular}

were given as much time as necessary to complete memorygeneration trials, and each trial component was self-paced. A key press indicated memory retrieval and initiated the question "Is the memory specific?" together with the definition of specificity. After typing yes or no, participants clicked next and were prompted on a new screen to type a short description of the memory. Following their description, they again clicked next and proceeded to a screen requesting that they rate the vividness of the memory on a 5-point scale. After clicking next a final time, they typed a one-word title for the memory to help them recall it later; they stated the cue and the title aloud for recording by the experimenter, who was otherwise blind to memory production. The experimenter asked for corrections to duplicate titles and titles that matched experimental cues (both rare occurrences). Titles typically referred to the people or events uniquely described in each memory (e.g., "prom" in response to "extravagant" and "jobs" in response to "dependent"). Following two practice trials and 30 memorygeneration trials, participants completed a second VAS.

In the TNT phase, the experimenter explained that performance in avoiding thoughts of targets would be analyzed in relation to general cognitive ability. Cues included 10 emotional and 10 neutral cues from the generation phase, with the remaining 5 of each type reserved as baseline. Following TNT practice with the previous practice cues, these 20 cues each appeared for $4 \mathrm{~s}$ on 12 occasions, each time preserving the block order from the generation phase. Ten cues ( 5 emotional and 5 neutral) were presented in green, and participants were instructed to respond to them aloud with titles and to think about the corresponding memories. Incorrect or omitted titles were corrected by the experimenter. Ten cues were presented in red. We instructed participants to attend to red cues for their duration but to prevent the corresponding titles and memories from coming to mind, even after cue offset. Errors were followed by a display of large red Xs.

Following TNT, participants completed a third VAS, and then, as a purported measure of their cognitive ability, they attempted Set E of Raven's Standard Progressive Matrices (Raven, 1960) for 10 min before the final recall test began. Cue order on the test preserved the same block order used during generation. To each cue, participants first signaled recall with a key press and then typed the memory's title and short description. Failure to signal within $6 \mathrm{~s}$ automatically produced the title and description requests (which could be completed with "?" if forgotten); typing of titles and descriptions was self-paced. Reminders to produce specific memories were not repeated, but the experimenter stressed the importance of reporting the same titles and memories exactly as produced during generation.

\section{Results}

\section{Memory specificity}

Two judges, blind to conditions, independently determined the status (overgeneral or specific) of each initially generated memory and (separately) each reproduced memory on the 
final test. (Memories were judged as specific if they clearly denoted an event that occurred within 1 day.) The judgments were identical on $97 \%$ of memories, and the few disagreements were resolved by a third judge. The proportion of specific memories (out of the total number produced) was submitted to a mixed-design analysis of variance, with TNT instruction (respond, baseline, or suppress), cue emotionality (neutral or emotional), and phase (generation or final recall) as within-subjects factors and valence of the emotional cues (positive or negative) and group (dysphoric or nondysphoric) as between-subjects factors. The significance level was set at .05 . Significant main effects qualified by significant interactions are not reported.

The first important outcome was the predicted interaction of phase and instruction, $F(2,112)=5.38$, mean squared error $(M S E)=.011, p=.006, \eta_{\mathrm{p}}^{2}=.09$. Relevant means are illustrated in Figure 1. Tests of simple main effects found nonsignificant differences in the generation phase between the proportion of specific memories to be responded $(M=.95$, $S D=.07)$, reserved as baseline $(M=.96, S D=.07)$, or suppressed $(M=.96, S D=.09)(F<1.0)$ but a significant difference among responded $(M=.90, S D=.12)$, baseline $(M=.90$, $S D=.13)$, and suppressed memories $(M=.84, S D=.15)$ in final recall, $F(2,112)=5.58, M S E=.022 p=.005, \eta_{\mathrm{p}}{ }^{2}=.06$. A planned comparison revealed that the specificity of suppressed memories was reduced relative to baseline memories, $F(1,56)=5.57, M S E=.026, p=.022, \eta_{\mathrm{p}}^{2}=.05$.

The phase-by-instruction interaction was not significantly qualified by other effects in the overall design $(p>.12)$. Nevertheless, it would be misleading if we failed to call attention to the pattern of means for baseline and suppress cues shown in Table 2. The below-baseline specificity reduction was -.03 for positive cues (and .08 for neutral cues received by the same participants), whereas it was as large as .12 in the negative condition.

As the only significant higher order interaction in the design, the three-way interaction among phase, valence, and

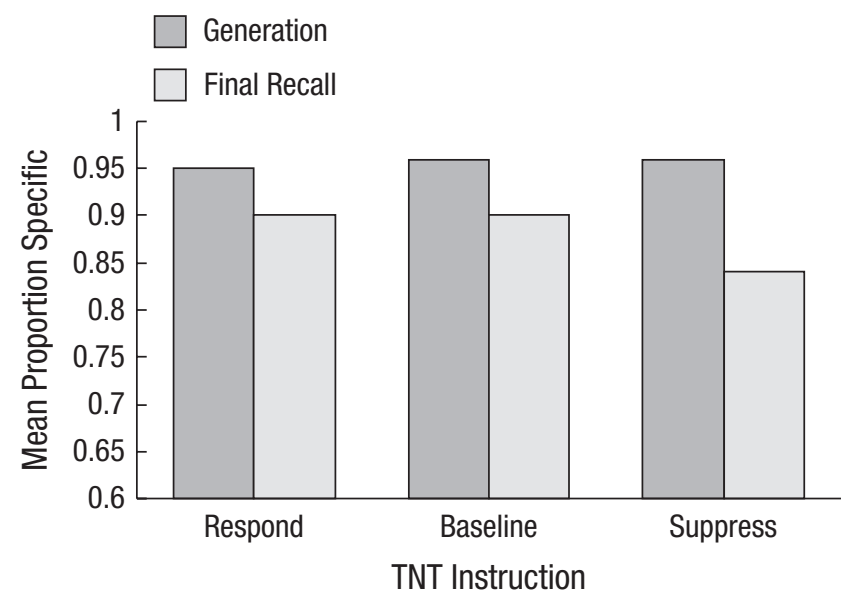

Figure I. Mean proportion of specific responded, baseline, and suppressed memories produced in the generation phase and then in final recall. TNT = think/no-think
Table 2. Mean Proportion of Specific Memories During Final Recall

\begin{tabular}{|c|c|c|c|c|}
\hline \multirow[b]{2}{*}{ Instruction } & \multicolumn{2}{|c|}{ Positive condition } & \multicolumn{2}{|c|}{ Negative condition } \\
\hline & $\begin{array}{c}\text { Positive } \\
\text { cue }\end{array}$ & $\begin{array}{c}\text { Neutral } \\
\text { cue }\end{array}$ & $\begin{array}{c}\text { Negative } \\
\text { cue }\end{array}$ & $\begin{array}{c}\text { Neutral } \\
\text { cue }\end{array}$ \\
\hline \multicolumn{5}{|l|}{ Generation } \\
\hline Responded & $.94(.089)$ & $.94(.107)$ & $.97(.076)$ & $.95(.086)$ \\
\hline Suppressed & $.98(.06 \mathrm{I})$ & $.95(.104)$ & $.97(.092)$ & $.93(.14 I)$ \\
\hline Baseline & $.95(.086)$ & $.99(.037)$ & $.96(.081)$ & $.94(.130)$ \\
\hline \multicolumn{5}{|l|}{ Final recall } \\
\hline Responded & $.88(.154)$ & $.90(.149)$ & $.91(.120)$ & $.90(.154)$ \\
\hline Suppressed & $.91(.118)$ & $.85(.158)$ & $.82(.210)$ & $.78(.237)$ \\
\hline Baseline & $.88(.180)$ & $.93(.137)$ & $.94(.145)$ & $.84(.209)$ \\
\hline
\end{tabular}

Note: Standard deviations are in parentheses.

group did not involve instruction during the TNT phase but is nonetheless notable, $F(1,56)=4.69, M S E=.017, p=.035$, $\eta_{\mathrm{p}}{ }^{2}=.08$. The Phase $\times$ Valence interaction (not found for nondysphoric participants, $p=.457$ ) was significant for dysphoric participants, $F(1,28)=4.78, M S E=.020, p=.037, \eta_{\mathrm{p}}{ }^{2}=.15$. As shown in Table 1, the reduction in the specificity of dysphoric students' responses to all cues was greater if half of their cues had been negative (compared to half positive), regardless of the role played by the cues during TNT.

Finally, the two remaining significant interactions did not involve the experimental phase. First, the effect of instruction depended on the valence of the emotional cues, $F(2,112)=$ $3.47, \operatorname{MSE}=.018, p=.034, \eta_{\mathrm{p}}{ }^{2}=.06$. The comparison of baseline and suppressed memories was significant when the emotional cues were negative, $F(1,28)=4.99, M S E=.025$, $p=.034, \eta_{\mathrm{p}}^{2}=.15$, but not when they were positive $(F<$ 1.0). Second, the difference in response specificity to neutral versus emotional cues depended on the valence of the latter, $F(1,56)=5.09, M S E=.016, p=.028, \eta_{\mathrm{p}}{ }^{2}=.08$. Participants responded to neutral cues with uniformly high levels of specificity ( $M=.93$ in each valence group) but differentially to emotional cues (positive group: $M=.93$; negative group: $M=$ .89). Supplemental materials include means and standard deviations according to each factor in the full design.

\section{Memory accuracy}

A memory was deemed accurate if it reported the same event as initially recalled. The omission or addition of event details was not taken into account when determining accuracy, unless the details provided in the final test directly contradicted those provided initially. The analysis of variance in the proportion of accurate memories yielded two significant effects. The first was a main effect of instruction, $F(2,112)=31.79, M S E=$ $.025, p<.001, \eta_{\mathrm{p}}{ }^{2}=.36$. Responded memories were recalled more accurately $(M=.97, S D=.09)$ than both suppressed $(M=.84, S D=.19)$ and baseline memories $(M=.82, S D=$ .19). The second significant outcome was an interaction 
between emotion and valence, $F(1,56)=5.27, M S E=.022$, $p=.025, \eta_{\mathrm{p}}{ }^{2}=.09$. Participants in the negative valence condition recalled memories associated with negative cues less accurately $(M=.81, S D=.18)$ than those associated with neutral cues $(M=.88, S D=.14)$, whereas those in the positive valence condition recalled memories associated with positive $(M=.90, S D=.13)$ and neutral $(M=.90, S D=.13)$ cues with equal accuracy. ${ }^{3}$

\section{Memory valence}

To examine whether the memories themselves varied emotionally in ways consistent with the cues, we asked two individuals, blind to conditions, to rate the memories in each phase from 1 (extremely positive) to 9 (extremely negative). Analysis of their averaged ratings revealed four significant interactions. Across both phases, the negative condition produced more negative memories in response to emotional cues $(M=6.29$ vs. 4.61 in the positive condition) but similarly rated memories in response to neutral cues $(M=5.71$ vs. 5.56), $F(1,56)=$ $128.59, M S E=.817, p<.001, \eta_{\mathrm{p}}^{2}=.70$.

Means relevant to the remaining three significant interactions are shown in Table 1. The interaction of valence with phase, $F(1,56)=15.00, M S E=.130, p<.001, \eta_{\mathrm{p}}{ }^{2}=.21$, indicated that the ratings did not change in the positive condition but became less negative in the negative condition. The interaction of group with phase was also significant, $F(1,56)=$ $7.48, M S E=.130, p=.008, \eta_{\mathrm{p}}{ }^{2}=.12$; only the memories produced by dysphoric participants decreased in negativity on the final test. Last, the interaction of group with the valence of the emotional cues was significant, $F(1,56)=5.12, M S E=.782$, $p=.028, \eta_{\mathrm{p}}{ }^{2}=.08$; the difference between memories produced by participants who received negative cues and those who received positive cues was larger in the dysphoric group than in the nondysphoric group. Supplemental materials contain a table of all means and standard deviations.

\section{Emotional consequences of TNT}

Of the three VAS scales, only distressed/calm revealed changes across the three administrations. The three-way interaction of phase, valence, and group was significant, $F(2,106)=4.00$, $M S E=168.57, p=.021, \eta_{\mathrm{p}}{ }^{2}=.07$. Follow-up tests within each group revealed only a nonsignificant trend $(p=.085)$ for the dysphoric participants to be less distressed after generating memories to negative cues (see Table 1).

\section{Discussion}

Consistent with traditional TNT findings (see M. C. Anderson \& Huddleston, 2012), we found evidence for impaired recall of suppressed memories relative to baseline memories. Suppressed memories became less specific following TNT suppression. In addition, reduced specificity, regardless of TNT instructions, characterized the final recall of dysphoric students who had received negative cues, and their memories became less negative than they were at the outset.

As anticipated, our adaptation of the TNT paradigm did not yield below-baseline forgetting in the traditional sense. Unlike the materials used in more standard TNT paradigms, the targets submitted to suppression practice in the present study were emotional, self-generated, personally relevant, and related to the associated cues. Given these critical differences, our failure to generalize the effect to autobiographical accuracy hardly seems surprising. However, the reductions in specificity observed in our study correspond to the typical below-baseline forgetting observed in the TNT task in that they involve a failure to recall autobiographical memory details (see Wessel \& Hauer, 2006). For example, in response to the cue "illogical," one participant initially retrieved, "My sister accused me of turning our parents against her because they didn't want her to go to her favorite college" and, following suppression practice, recalled, "My parents didn't like my sister's favorite college." The initial response clearly denotes a single event, whereas the memory recalled during the final test omits autobiographical details. Another participant, in response to the cue "dependent," initially reported, "I was unable to find a job one summer, making me feel bad for being so dependent on my parents one day when my friends were talking about their jobs and wages" and, following suppression, recalled, "I couldn't find a summer job one year and felt bad for being so dependent on my parents financially." The initially recalled event describes an emotion experienced on a single day, whereas the final memory contained a less detailed description of feelings that endured over an extended period of time.

Although the below-baseline reduction in specificity did not significantly interact with the valence of emotional cues, it appeared more obviously in the recall of participants who received negative cues, and their memories also became less negative on the final recall test. This pattern seems consistent with previous TNT studies reporting greater rates of belowbaseline forgetting for negative relative to positive targets (e.g., Joormann et al., 2005; Lambert et al., 2010). Memories associated with negative cues were also recalled less accurately overall, supporting the idea that negative materials may be more vulnerable to forgetting.

Unlike other TNT experiments (Hertel \& Gerstle, 2003; Joormann et al., 2009), we did not find evidence for depression-related impairments in either forgetting or specificity reduction. Instead, dysphoric students who had initially responded to negative emotional cues subsequently recalled less specifically, regardless of the emotionality of the test cue or its role in the TNT phase. This outcome suggests a possible dysphoric tendency to engage in avoidant coping (Williams et al., 2007). A similar pattern has been found in other experiments on suppression-induced overgeneral memory, in which suppression of a particular memory reduced the specificity of unrelated memories on a subsequent test (Dalgleish \& Yiend, 2006; Schönfeld et al., 2007). In our case, at least, these very 
general effects might simply be due to the absence of reminders to be specific that had been provided in the previous generation phase-reminders potentially not needed by the nondysphoric students - if it were not for the fact that the dysphoric students receiving positive cues performed well.

The memories of dysphoric participants, independent of TNT instruction, and the suppressed memories of both participant groups exposed to negative cues became not only less specific in the final test but also less negative. The concurrent reductions in specificity and negativity are consistent with the functional avoidance hypothesis proposed by Williams et al. (2007), in which reduced specificity occurs as an avoidant coping strategy to limit the emotional disturbance associated with re-experiencing details from negative life events. Previous studies have also provided evidence for a relationship between memory specificity and affect. Recalling a high proportion of specific memories is associated with having a more negative perception of a frustrating event (e.g., Raes, Hermans, de Decker, Eelen, \& Williams, 2003) and greater distress following negative life events (Hermans et al., 2008). Because memories produced by our negative group were more negative than memories in our positive group, students in the negative group might have been motivated to avoid the details of those memories and therefore to produce less specific and less negative recall on the final test. And for dysphoric students in the negative group, such avoidance seemed to have generalized to all cues, regardless of previous suppression attempts.

As an early attempt to examine suppression-induced effects on autobiographical memories, our experiment reveals limitations for future research to address. First, unlike more typical TNT paradigms, our adaptation of the TNT procedure did not include a test to ensure (prior to the TNT phase) equivalent "learning" of materials designated for responding, baseline, or suppressing; in our case, the concern is to establish rough equivalencies in linkages between memories and cues. Our exclusion of such a phase was prompted by time constraints and concerns about participant fatigue, because most sessions lasted approximately 2 hours and some lasted longer. Instead, we assumed that any differences would be random across instructional conditions. Second, our retention interval following the TNT phase was short (because of the same concerns), but it is important to discover whether the effects of suppression-practice would increase or decrease with longer delays before the final test (see M. C. Anderson \& Huddleston, 2012; Hotta \& Kawaguchi, 2009). Third, we hope that future research will examine the conditions for achieving autobiographical forgetting beyond the reduction of specificity, and we suspect that they involve the practice of suppression across multiple occasions and contexts. Thus, forgetting of autobiographical events might be found on a continuum that ranges from the forgetting of details to the forgetting of gist. Finally, experimental attention surely should be focused on the neural mechanisms underlying autobiographical memory suppression in comparison to the mechanisms of SIF involving laboratory materials (see M. C. Anderson et al., 2004).
In conclusion, we offer a few thoughts about the implications of our findings for managing memories in emotionally disordered populations. At the outset, we suggested that the ability to avoid recalling details of negative life experiences in the face of potential reminders may promote resilience through the interruption or prevention of ruminative episodes. This suggestion, derived as it is from the TNT method of suppressing formerly recalled memories, clearly applies only to memories that have all too readily come to mind on previous occasions. As such, it stands in clear contrast to memorial experience in posttraumatic stress disorder (PTSD) and the corresponding recommendations regarding clinical treatment (see Krans, Näring, Becker, \& Holmes, 2009). In that literature, memory suppression is associated with the onset of maladaptive reactions to trauma, whereas memory "expression" soon after the trauma reduces early involuntary, intrusive memories (flashbacks) even to the point of reducing or eliminating PTSD symptoms. We therefore concur with an opinion expressed in a letter by Holmes, Moulds, and Kavanagh (2007) that results from TNT experiments should not be generalized to trauma-related memories. Nevertheless, we recommend experimental explorations concerning the clinical value in targeted suppression of emotional but nontraumatic memories that live on in ruminative episodes, long past their therapeutic usefulness (e.g., a final conversation with a former partner, a poorly delivered conference talk, a stupid remark made to a colleague). In such cases, it appears that with repeated practice, the specificity and emotional potency of autobiographical experiences can be reduced, and the "unforgettable" can, at least in part, be forgotten.

\section{Declaration of Conflicting Interests}

The authors declared that they had no conflicts of interest with respect to their authorship or the publication of this article.

\section{Acknowledgments}

We thank Allison Ford, Megan Murphy, Nousha Parkhill, and Virginia Wallette for help in scoring.

\section{Notes}

1. While this report was under review, we discovered that Noreen and MacLeod (2012) also found evidence of SIF of autobiographical memories.

2. We maintained data from students who scored slightly outside the initial boundaries out of concern that our task might have temporarily affected the scores at the end of the session. Under instructions from the Institutional Review Board, we removed the suicide item from the BDI-II; possible scores therefore ranged from 0 to 60 . Nondysphoric participants were also chosen for their slightly repressive tendencies, as evidenced by scores above the median (15) on the Social Desirability Scale (Crowne \& Marlowe, 1960) and below the median (39) on the trait version of the State-Trait Anxiety Inventory (Spielberger, Gorsuch, Lushene, Vagg, \& Jacobs, 1983; see also Myers \& Derakshan, 2004).

3. Latencies to retrieve memories showed the same pattern of effects as did the gist-accuracy data; longer latencies occurred in the same 
conditions as lower accuracies. A table of means and standard deviations is included in supplemental materials.

\section{References}

Anderson, M. C., \& Green, C. (2001). Suppressing unwanted memories by executive control. Nature, 410, 366-369.

Anderson, M. C., \& Huddleston, E. (2012). Towards a cognitive and neurobiological model of motivated forgetting. In R. F. Belli (Ed.), True and false recovered memories: Toward a reconciliation of the debate (Nebraska Symposium on Motivation, Vol. 58, pp. 53-120). New York: Springer.

Anderson, M. C., Ochsner, K. N., Kuhl, B., Cooper, J., Roberston, E., Gabrieli, S. W., . . . Gabrieli, J. D. (2004). Neural systems underlying the suppression of unwanted memories. Science, 303, 232-235.

Anderson, N. (1968). Likableness ratings of 555 personality-trait words. Journal of Personality and Social Psychology, 9, 272-379.

Beck, A. T., Steer, R. A., \& Brown, G. K. (1996). Beck Depression Inventory manual (2nd ed.). San Antonio, TX: Psychological Corporation.

Crowne, D. P., \& Marlowe, D. A. (1960). A new scale of social desirability independent of psychopathology. Journal of Consulting Psychology, 24, 349-354.

Dalgleish, T., \& Yiend, J. (2006). The effects of suppressing a negative autobiographical memory on concurrent intrusions and subsequent autobiographical recall in dysphoria. Journal of Abnormal Psychology, 115, 467-473.

Depue, B. E., Banich, M. T., \& Curran, T. (2006). Suppression of emotional and nonemotional content in memory: Effects of repetition on cognitive control. Psychological Science, 17, 441-447.

Dozois, D. J. A., Dobson, K. S., \& Ahnberg, J. L. (1998). A psychometric evaluation of the Beck Depression Inventory-II. Psychological Assessment, 10, 83-89.

Hanslmayr, S., Leipold, P., \& Bauml, K.- H. (2010). Anticipation boosts forgetting of voluntarily suppressed memories. Memory, 18, 252-257.

Hermans, D., de Decker, A., de Peuter, S., Raes, F., Eelen, P., \& Williams, J. M. (2008). Autobiographical memory specificity and affect regulation: Coping with a negative life event. Depression and Anxiety, 25, 787-792.

Hertel, P. T., \& Gerstle, M. (2003). Depressive deficits in forgetting. Psychological Science, 14, 573-578.

Hertel, P. T., Large, D., Stück, E. D., \& Levy, A. (2012). Suppressioninduced forgetting on a free-association test. Memory, 20, 100 109.

Hertel, P. T., \& McDaniel, L. (2010). The suppressive power of positive thinking: Aiding suppression-induced forgetting in repressive coping. Cognition and Emotion, 24, 1239-1249.
Holmes, E. A., Moulds, M. L., \& Kavanagh, D. (2007). Memory suppression in PTSD treatment [letter to the editor]. Science, 318, 1722.

Hotta, C., \& Kawaguchi, J. (2009). Self-initiated use of thought substitution can lead to long term forgetting. Psychologia, 52, 41-49.

Joormann, J., Hertel, P. T., Brozovich, F., \& Gotlib, I. H. (2005). Remembering the good, forgetting the bad: Intentional forgetting of emotional material in depression. Journal of Abnormal Psychology, 114, 640-648.

Joormann, J., Hertel, P. T., LeMoult, J., \& Gotlib, I. H. (2009). Training forgetting of negative material in depression. Journal of Abnormal Psychology, 118, 34-43.

Krans, J., Näring, G., Becker, E. S., \& Holmes, E. A. (2009). Intrusive trauma memory: A review and functional analysis. Applied Cognitive Psychology, 23, 1076-1088.

Lambert, A. J., Good, K. S., \& Kirk, I. J. (2010). Testing the repression hypothesis: Effects of emotional valence on memory suppression in the think-no think task. Consciousness and Cognition, 19, 281-293.

Myers, L. B., \& Derakshan, N. (2004). To forget or not to forget: What do repressors forget and when do they forget: Cognition and Emotion, 18, 495-511.

Noreen, S., \& MacLeod, M. D. (2012). It's all in the detail: Intentional forgetting of autobiographical memories using the autobiographical think/no-think task. Journal of Experimental Psychology: Learning, Memory, and Cognition. Advance online publication. doi:10.1037/a0028888

Raes, F., Hermans, D., de Decker, A., Eelen, P., \& Williams, J. M. G. (2003). Autobiographical memory specificity and affect regulation: An experimental approach. Emotion, 3, 201-206.

Raven, J. C. (1960). Guide to the standard progressive matrices. London: Lewis.

Schönfeld, S., Ehlers, A., Böllinghaus, I., \& Rief, W. (2007). Overgeneral memory and suppression of trauma memories in posttraumatic stress disorder. Memory, 15, 339-352.

Spielberger, C. D., Gorsuch, R. L., Lushene, R., Vagg, P. R., \& Jacobs, G. A. (1983). Manual for the State-Trait Anxiety Inventory. Palo Alto, CA: Consulting Psychologists Press.

Wessel, I., \& Hauer, B. (2006). Retrieval-induced forgetting of autobiographical memory details. Cognition and Emotion, 20, 430 447.

Williams, J. M. G., Barnhofer, T., Crane, C., Herman, D., Raes, F., Watkins, E., \& Dalgleish, T. (2007). Autobiographical memory specificity and emotional disorder. Psychological Bulletin, 133, 122-148.

Williams, J. M. G., \& Broadbent, K. (1986). Autobiographical memory in suicide attempters. Journal of Abnormal Psychology, 95, 144-149. 